BNL-112657-2016-JA

\title{
Energy Level Shifts at the Silica/Ru(0001) Heterojunction Driven by Surface and Interface Dipoles
}

\author{
Mengen Wang, Jian-Qiang Zhong, John Kestell, \\ Iradwikanari Waluyo, Dario J. Stacchiola, J. Anibal Boscoboinik, Deyu Lu
}

Submitted to the Journal of Topics in Catalysis

September 2016

Center for Functional Nanomaterials

Brookhaven National Laboratory

\author{
U.S. Department of Energy \\ USDOE Office of Science (SC), \\ Basic Energy Sciences (BES) (SC-22)
}

\footnotetext{
Notice: This manuscript has been authored by employees of Brookhaven Science Associates, LLC under Contract No. DE- SC0012704 with the U.S. Department of Energy. The publisher by accepting the manuscript for publication acknowledges that the United States Government retains a non-exclusive, paidup, irrevocable, world-wide license to publish or reproduce the published form of this manuscript, or allow others to do so, for United States Government purposes.
} 


\section{DISCLAIMER}

This report was prepared as an account of work sponsored by an agency of the United States Government. Neither the United States Government nor any agency thereof, nor any of their employees, nor any of their contractors, subcontractors, or their employees, makes any warranty, express or implied, or assumes any legal liability or responsibility for the accuracy, completeness, or any third party's use or the results of such use of any information, apparatus, product, or process disclosed, or represents that its use would not infringe privately owned rights. Reference herein to any specific commercial product, process, or service by trade name, trademark, manufacturer, or otherwise, does not necessarily constitute or imply its endorsement, recommendation, or favoring by the United States Government or any agency thereof or its contractors or subcontractors. The views and opinions of authors expressed herein do not necessarily state or reflect those of the United States Government or any agency thereof. 
BNL-112657-2016-JA

\title{
Energy Level Shifts at the Silica/Ru(0001) Heterojunction Driven by Surface and Interface Dipoles
}

\author{
Mengen Wang ${ }^{1,2} \cdot$ Jian-Qiang Zhong $^{1} \cdot$ John Kestell $^{1} \cdot$ Iradwikanari Waluyo $^{3}$. \\ Dario J. Stacchiola ${ }^{1}$ J. Anibal Boscoboinik ${ }^{1} \cdot$ Deyu Lu $^{1}$
}

\begin{abstract}
Charge redistribution at heterogeneous interfaces is a fundamental aspect of surface chemistry. Manipulating the amount of charges and the magnitude of dipole moments at the interface in a controlled way has attracted tremendous attention for its potential to modify the activity of heterogeneous catalysts in catalyst design. Two-dimensional ultrathin silica films with well-defined atomic structures have been recently synthesized and proposed as model systems for heterogeneous catalysts studies. R. Wlodarczyk et al. (Phys. Rev. B, 85, 085403 (2012)) have demonstrated that the electronic structure of silica/ $\mathrm{Ru}(0001)$ can be reversibly tuned by changing the amount of interfacial chemisorbed oxygen. Here we carried out systematic investigations to understand the underlying mechanism through which the electronic structure at the silica/ $\mathrm{Ru}(0001)$ interface can be tuned. As corroborated by both in situ X-ray photoelectron spectroscopy and density functional theory calculations, the observed interface
\end{abstract}

Jian-Qiang Zhong and Mengen Wang contributed equally to this work.

Electronic supplementary material The online version of this article (doi:10.1007/s11244-016-0704-x) contains supplementary material, which is available to authorized users.

J. Anibal Boscoboinik

jboscoboinik@bnl.gov

$\triangle$ Deyu Lu

dlu@bnl.gov

1 Center for Functional Nanomaterials, Brookhaven National Laboratory, Upton, NY 11973, USA

2 Materials Science and Engineering Department, Stony Brook University, Stony Brook, NY 11790, USA

3 Photon Science Division, National Synchrotron Light Source II, Brookhaven National Laboratory, Upton, NY 11973, USA energy level alignments strongly depend on the surface and interfacial charge transfer induced dipoles at the silica/ $\mathrm{Ru}(0001)$ heterojunction. These observations may help to understand variations in catalytic performance of the model system from the viewpoint of the electronic properties at the confined space between the silica bilayer and the $\mathrm{Ru}(0001)$ surface. The same behavior is observed for the aluminosilicate bilayer, which has been previously proposed as a model system for zeolites.

\section{Introduction}

Two-dimensional ultrathin silica films with well-defined atomic structures have recently attracted widespread interest due to their capabilities in modeling and understanding the structure-reactivity relationships in heterogeneous catalysts based on $\mathrm{SiO}_{2}$, either as a support for metal catalysts [1,2], or as part of the active structure [3], such as the case of zeolites [4]. In the past decade, intensive research efforts have been devoted to the preparation of well-ordered crystalline silica films on diverse metals, such as $\mathrm{Mo}(112), \mathrm{Ni}(111), \operatorname{Pd}(100), \operatorname{Pt}(111)$, and $\mathrm{Ru}(0001)$ [5-10]. In particular, free-standing silica and aluminosilicate bilayer films with corner-sharing tetrahedra $\left(\mathrm{TO}_{4}\right.$, with $\mathrm{T}=\mathrm{Si}$ or $\mathrm{Al}$ ) have been successfully grown on noble metal substrates, in which the bilayer films interact weakly with the support via van der Waals (vdW) forces $[9,10]$. The relatively weak interaction between the metallic substrate and the ultrathin (alumino) silicate film makes it possible to explore the fundamental aspects of the catalytic activity and selectivity by using these model systems [4]. Moreover, small molecules can intercalate and react at the interface [11-13], which provides a new playground to 
study chemical reactions at confined spaces using surface science methods [12]. Another important feature about this system, arising from the weak interactions between their components, is that the distance between the silica bilayer and the $\mathrm{Ru}(0001)$ surface can be tuned by the type and concentration of adsorbed molecules on the $\mathrm{Ru}(0001)$ surface [14].

Recently, the electronic properties involved in heterogeneous oxidation catalysts have been explored by $\mathrm{M}$. Eichelbaum et al. in situ using ambient-pressure X-ray photoelectron spectroscopy (AP-XPS) [15]. It has been shown that a dynamic surface potential barrier can be used as a rational descriptor of catalytic selectivity under oxidation reactions [15]. Notwithstanding the great interest on the effect of interfacial electronic structures on catalytic performance, the origin of the dynamic surface potential barrier and its relation to the catalytic selectivity have not been fully understood. For example, for the case of silica/ $\mathrm{Ru}(0001)$ interfaces, R. Wlodarczyk et al. showed that changes in the coverage of chemisorbed oxygen on $\mathrm{Ru}(0001)$ result in gradual changes of the silica/Ru electronic states [16]. However, the detailed underlying mechanism remains unclear.

The study presented here extends the previous work by the groups of Freund and Sauer [16], by carrying out X-ray photoelectron spectroscopy (XPS) and density functional theory (DFT) calculations to reveal the mechanisms of the electronic state tuning at the silica/Ru(0001) interfaces. The main focus is on energy levels of the silica films upon the addition or reduction of chemisorbed oxygen on the $\mathrm{Ru}(0001)$ substrate. We found that the charge transfer from $\mathrm{Ru}$ to chemisorbed oxygen atoms induces surface dipole moments, which has an opposite sign of the interface dipole moments caused by the charge transfer between silica films and the $\mathrm{Ru}$ substrate. These two competing effects, depending on the amount of chemisorbed oxygen, dominate the energy level alignment at the silica/Ru(0001) interfaces and the core-level binding energies in the silica films.

\section{Experimental and Computational Methods}

The $\mathrm{Ru}(0001)$ single crystal surface was cleaned with cycles of $\mathrm{Ar}^{+}$sputtering and annealing at $1400 \mathrm{~K}$. It was then exposed to $3 \times 10^{-6}$ mbar $\mathrm{O}_{2}$ at $1200 \mathrm{~K}$ in order to form a chemisorbed oxygen overlayer. The silica and aluminosilicate films were grown on the oxygen pre-covered Ru surface as described in detail elsewhere [9, 10]. Briefly, $\mathrm{Si}$ (or Si and $\mathrm{Al}$ ) was thermally evaporated onto the $\mathrm{O} / \mathrm{Ru}(0001)$ surface at room temperature under $2 \times 10^{-7}$ mbar of $\mathrm{O}_{2}$, followed by oxidation at $1200 \mathrm{~K}$ in $3 \times 10^{-6}$ mbar $\mathrm{O}_{2}$ for $10 \mathrm{~min}$ and then slowly cooled down in the $\mathrm{O}_{2}$ environment. In-situ XPS measurements were carried out in an ultrahigh vacuum (UHV) system using $\mathrm{Mg} \mathrm{K} \alpha$ $(\mathrm{h} v=1253.6 \mathrm{eV})$ as the excitation source. Vacuum level shifts were determined from the secondary electron cutoff at the low kinetic energy part of the XPS spectra with a $-15 \mathrm{~V}$ sample bias. AP-XPS measurements were carried out at the CSX-2 beamline of the National Synchrotron Light Source II (NSLS-II) [12]. A photon energy of $750 \mathrm{eV}$ was used in our studies, which was calibrated and referenced to the Fermi level of the $\mathrm{Ru}(0001)$ substrates. Infrared reflection absorption spectroscopy (IRRAS) experiments were carried out in a home-built UHV system equipped with a Bruker Vertex 70 spectrometer [17]. This system is also capable of polarization modulation (PM) IRRAS experiments at pressures up to $1 \mathrm{Atm}$. The beam is reflected from the surface plane at an angle $8^{\circ}$ and the signal measured with a liquid-nitrogen-cooled MCT detector. The chamber has $\mathrm{BaF}_{2}$ windows allowing IR light to enter and exit the chamber and to withstand the potentially high pressures the instrument is capable of.

DFT calculations were performed using projector augmented-wave method implemented in the Vienna Ab initio simulation package (VASP) [18, 19]. The consistent exchange van der Waals density functional (vdW-DF-cx) $[20,21]$ was used to describe the non-local vdW interactions in the silica/Ru(0001) heterojunction. The choice of vdW-DF-cx was justified by its good performance for both metallic systems [20] and bulk chabazite tested against PBE [22, 23], several other flavors of vdW-DFs implemented in VASP [24] including optB88-vdW and optB86bvdW [25], and empirical vdW methods PBE-D [22] [6] and PBE-D3(BJ) [27, 28] (see Supporting Information for details). A kinetic energy cutoff of $800 \mathrm{eV}$ was used for bulk ruthenium together with a $28 \times 28 \times 18 \mathrm{k}$-point grid for Brillouin zone sampling. For siliceous chabazite, a $700 \mathrm{eV}$ cutoff was used with $\Gamma$ point sampling. Such high kinetic energy cutoffs are required to reach the numerical convergence for vdW-DF-cx using hard pseudopotentials [24].

The substrate of the silica/Ru(0001) heterojunction was modeled by five layers of ruthenium in a $2 \times 2$ supercell ( $a=5.392 \AA$ and $b=9.339 \AA$ ). In the surface normal direction, the super cell size was chosen as $c=27 \AA$ to ensure the vacuum region to be at least $10 \AA$ thick. A kinetic energy cutoff of $800 \mathrm{eV}$ and an $8 \times 4 \times 1 \mathrm{k}$-point grid were used. The silica film and the top two layers of the substrate were relaxed during the structure optimization until forces were smaller than $0.01 \mathrm{eV} / \AA$. Due to the existence of the sizable surface and interface dipole moments, the dipole correction method [29] was used to correct the spurious electrostatic interaction with image cells. The core-level binding energies $\left(E_{B E}\right)$ were calculated using the transition state model $[30,31]$ : 


$$
E_{B E}=\int_{0}^{1} \varepsilon(\eta) d \eta \approx \varepsilon(0.5)
$$

where $\eta(0 \leq \eta \leq 1)$ is the occupation number. $\varepsilon(\eta)$ is the Kohn-Sham (KS) core level eigenvalue (referred to the Fermi level at ground state) when the core level is occupied with $\eta$ electrons. The excited core electrons in a finite supercell can cause spurious changes in the charge distribution at the interface, which will introduce an error to the calculated $E_{B E}$. In order to eliminate this error, we calculated core level orbital energies using $2 \times 2(a=5.392 \AA$ and $b=9.339 \AA), 4 \times 2(a=10.784 \AA$ and $b=9.339 \AA)$ and $8 \times 4(a=21.568 \AA$ and $b=18.678 \AA)$ supercells, and the results are extrapolated to the infinite supercell size limit. All $E_{B E}$ values are given relative to that of chemisorbed oxygen atoms of the heterojunction with the highest oxygen coverage.

\section{Results and Discussion}

The structures of chemisorbed oxygen on $\mathrm{Ru}(0001)$ have been well studied, with four different phases reported in the literature, namely, $p(2 \times 2)-\mathrm{O}$ [32], $p(2 \times 1)-\mathrm{O}$ [33], $(2 \times 2)-3 \mathrm{O}$ [34] and $(1 \times 1)-\mathrm{O}$ [35]. As previously reported, bilayer silica films can be grown on either $p(2 \times 1)-\mathrm{O} / \mathrm{Ru}(0001)$ or $(2 \times 2)-3 \mathrm{O} / \mathrm{Ru}(0001)$ surfaces depending on the preparation conditions $[9,36]$. For the current study, a $(2 \times 2)-3 \mathrm{O} / \mathrm{Ru}(0001)$ superstructure was obtained prior to the silica film preparation. It was previously suggested that the chemisorbed oxygen prevents $\mathrm{Si}$ atoms from diffusing into the $\mathrm{Ru}(0001)$ during the thermal evaporation [9]. The as-deposited $\mathrm{SiO}_{\mathrm{x}}$ film was post-annealed at $1200 \mathrm{~K}$ in $3 \times 10^{-6} \mathrm{mbar}_{2}$. Well-ordered bilayer silica films are then formed and all the silicon species are oxidized to $\mathrm{Si}^{4+}$, with a binding energy of $102.75 \mathrm{eV}$ as is revealed by XPS (green spectra in Fig. 1b) [36]. The bilayer nature of the film was corroborated by infrared reflection absorption spectroscopy (IRRAS). The corresponding $\mathrm{O} 1 \mathrm{~s}$ spectra (green spectra in Fig. 1a) show a main peak at $532.00 \mathrm{eV}$ and a shoulder peak at $529.80 \mathrm{eV}$, which are assigned to the $\mathrm{Si}-\mathrm{O}-\mathrm{Si}$ linkages in bilayer silica films and the chemisorbed oxygen on $\mathrm{Ru}\left(\mathrm{O}_{-}\right.$ $\mathrm{Ru})$ respectively [37]. A shoulder peak of $\mathrm{Ru} 3 d_{5 / 2}$ further confirms the existence of the chemisorbed oxygen at the interface as shown in Fig. 1c.

The interfacial chemisorbed oxygen coverage was estimated to be 0.42 monolayer (ML) for $\mathrm{O} / \mathrm{Ru}(0001)$ with asprepared bilayer silica film with reference to the $0.75 \mathrm{ML}$ of $(2 \times 2)-3 \mathrm{O} / \mathrm{Ru}(0001)$ and taking into account the attenuation by the silica film in the calculation. The asprepared bilayer silica was then annealed in UHV from 950 to $1200 \mathrm{~K}$. When the temperature is increased, the $\mathrm{O} 1 \mathrm{~s}$ peak from the $\mathrm{Si}-\mathrm{O}-\mathrm{Si}$ moieties gradually shifts to higher binding energy by $\sim 0.70 \mathrm{eV}$ (Fig. 1a), while the position of the $\mathrm{O} 1 s$ peak from $(\mathrm{O}-\mathrm{Ru})$ remains almost unchanged. This is similar to previous work where the $\mathrm{O} 1 \mathrm{~s}$ peak from silica films shifts to higher binding energy $\mathrm{b} \sim 0.8 \mathrm{eV}$ upon UHV annealing to $1150 \mathrm{~K}$ [16]. In parallel, the $\mathrm{Si}$ $2 p$ peak also shows a similar $0.70 \mathrm{eV}$ shift upon annealing (Fig. 1b). Christin Büchner et al. also found that the work function decreases by $0.8 \mathrm{eV}$ while $\mathrm{O} 1 s$ peak and $\mathrm{Si}$ $2 p$ peak shift to higher binding energy by $0.77 \mathrm{eV}$ after creating the O-poor film [2]. Both the intensity and the full width at the half maximum (FWHM) of the O $1 s$ and $\mathrm{Si}$ $2 p$ remain unchanged, indicating that the chemical composition and bonding configuration of the silica film stay intact. The increase in binding energies can be attributed to changes of the chemical states on the $\mathrm{Ru}$ substrate $[13,37,38]$. As shown in Fig. 1a and 1c, the features of the $\mathrm{O} 1 s$ and $\mathrm{Ru} 3 d$ peaks arising from the O-Ru moiety decrease by a factor of 2.6 as compared to the as-prepared bilayer silica upon annealing to $1200 \mathrm{~K}$ in UHV, indicating that the coverage of interfacial oxygen decreases from 0.42 to 0.16 ML. Simultaneously, the work function (or the vacuum level) of the system decreases from 6.45 to $5.50 \mathrm{eV}$. The silica/ $\mathrm{Ru}(0001)$ was then further reduced by annealing in $3 \times 10^{-6}$ mbar of $\mathrm{H}_{2}$ at $400 \mathrm{~K}$, resulting in $0.06 \mathrm{ML}$ chemisorbed oxygen on $\mathrm{Ru}(0001)$ as the orange spectra shows in Fig. 1. Consequently, the binding energies of $\mathrm{O} 1 s(\mathrm{Si}-\mathrm{O}-\mathrm{Si})$ and $\mathrm{Si} 2 p$ shift another 0.05-532.75 and $103.50 \mathrm{eV}$ respectively, while the work function further decreases to $5.35 \mathrm{eV}$.

The amount of interfacial chemisorbed oxygen can be reversibly tuned. As shown in Fig. 2, all silica-related core levels shift back to lower binding energies upon exposure to $2 \times 10^{-4} \mathrm{mbar}$ of $\mathrm{O}_{2}$ at $820 \mathrm{~K}$. The coverage of chemisorbed oxygen increases to $0.75 \mathrm{ML}$, which is attributed to the higher $\mathrm{O}_{2}$ pressure [12]. Similarly, upon reduction by exposing the surface to 0.1 mbar of $\mathrm{H}_{2}$ at $380 \mathrm{~K}$, all silicarelated core levels shift to higher binding energies again. The significantly attenuated $\mathrm{O} 1 s(\mathrm{O}-\mathrm{Ru})$ and $\mathrm{Ru} 3 d(\mathrm{O}-$ $\mathrm{Ru})$ peaks indicate that most of the chemisorbed oxygen at the interface desorbs. The valence band spectra in Fig. 2d also shows a decrease in intensity at $\sim 5 \mathrm{eV}$, corresponding to the reduced $\mathrm{O}-\mathrm{Ru}$ states [39]. The peak at $10.6 \mathrm{eV}$ is originated from the hybridization between the $\mathrm{O}_{2 p}$ and $\mathrm{Si}_{3 s /}$ ${ }_{3 p}$ states in the $\mathrm{Si}-\mathrm{O}-\mathrm{Si}$ linkage of the bilayer silica films [40]. These hybridized states also shift to higher binding energies, consistent with the silica-related core levels shifts.

By comparing the magnitude in core levels shift $(0.75 \mathrm{eV})$ and work function shift $(1.10 \mathrm{eV})$ in the silica film during the reduction of the Ru substrate (chemisorbed oxygen coverage decreases from 0.42 to $0.06 \mathrm{ML}$ ), it is likely that both the surface (i.e., O-Ru) and the interface 
Fig. 1 Interfacial chemisorbed oxygen dependent energy levels at the weakly interacted bilayer silica/Ru(0001) interface. The evolution of the XPS $(\mathrm{h} v=1253.6 \mathrm{eV})$ core level spectra of a O 1 s, b Si 2p, c Ru $3 \mathrm{~d}$, and $\mathbf{d}$ the XPS spectra at the low-kinetic energy part (secondary electron cutoff) upon heating the silica/ $\mathrm{Ru}(0001)$ from 950 to $1200 \mathrm{~K}$ in vacuum. e Plots the interfacial chemisorbed oxygen coverage dependent binding The black spectrum is clean $\mathrm{Ru}(0001)$ and the red spectrum is $(2 \times 2)-3 \mathrm{O} / \mathrm{Ru}(0001)$ (i.e., with $0.75 \mathrm{ML} \mathrm{O}$ ). The orange spectrum was collected after annealing the film in $3 \times 10^{-6}$ mbar of $\mathrm{H}_{2}$ at $400 \mathrm{~K}$ energies and work functions.
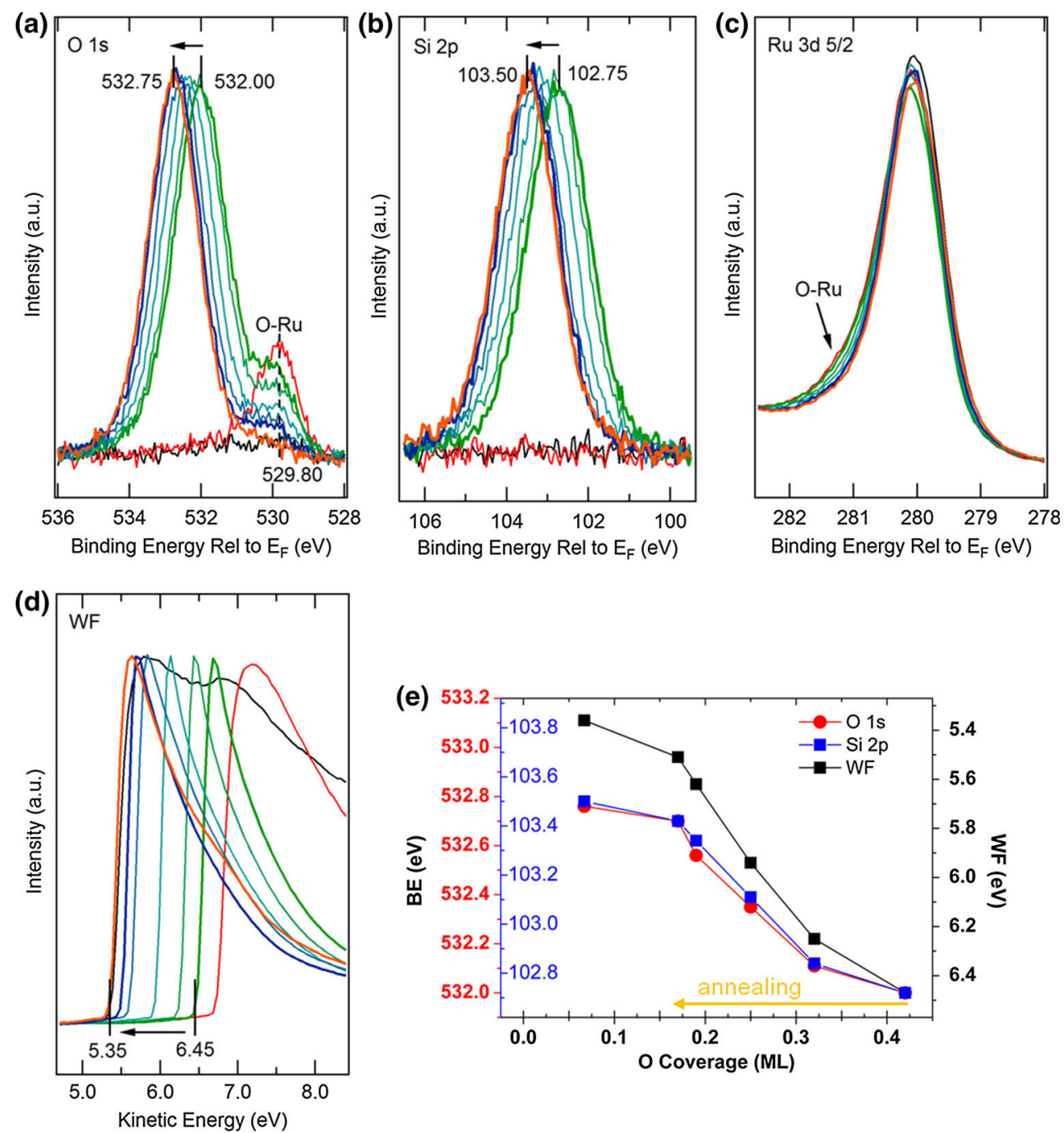

(i.e., silica/O-Ru) dipoles play important roles in determining the energy level shifts at the silica/ $\operatorname{Ru}(0001)$ heterojunction. We further explored the underlying mechanisms using DFT for the silica/Ru(0001) heterojunction with different amounts of interfacial chemisorbed oxygen. We denote the chemisorbed oxygen species as $\mathrm{O}(\mathrm{Ru})$, and the oxygen species in the corner-sharing $\mathrm{SiO}_{4}$ tetrahedra in silica films as $\mathrm{O}(\mathrm{Si})$. The silica/ $\mathrm{Ru}(0001)$ heterojunction was modeled as bilayer silica films $\left(\mathrm{SiO}_{2}\right)$ on $\mathrm{Ru}(0001)$. $\mathrm{Si}$ atoms in the bilayer are located on hollow sites of $\mathrm{Ru}(0001)$, and this model has been used in the literature [10]. In order to investigate the influence of $\mathrm{O}(\mathrm{Ru})$ on the electronic structure of silica films, we studied three oxygen coverages on $\mathrm{Ru}(0001)$ according to experimental conditions: $\mathrm{Ru}(0001), p(2 \times 2)-\mathrm{O} / \mathrm{Ru}(0001)$ and $p(2 \times 1)-\mathrm{O} /$ $\mathrm{Ru}(0001)$ as shown in Fig. 3. These models correspond to $\left(\mathrm{SiO}_{2}\right)_{8} / 0 \mathrm{O} / \mathrm{Ru}(0001),\left(\mathrm{SiO}_{2}\right)_{8} / 2 \mathrm{O} / \mathrm{Ru}(0001)$ and $\left(\mathrm{SiO}_{2}\right)_{8} /$ $4 \mathrm{O} / \mathrm{Ru}(0001)$, respectively, where $n \mathrm{O}(n=0,2$ or 4$)$ represents the number of $\mathrm{O}(\mathrm{Ru})$ in the unit cell (i.e., 0, 0.25,
$0.50 \mathrm{ML})$. At $n=0$, the silica film is physisorbed on the $\mathrm{Ru}$ substrate with a interlayer distance $\left(d\left(\mathrm{Ru}-\mathrm{O}_{\mathrm{Si}}\right)\right)$ of 2.84 $\AA$. As $n$ increases, the silica film is pushed away from the substrate. At $n=4, d\left(\mathrm{Ru}-\mathrm{O}_{\mathrm{Si}}\right)$ increases by as much as $1.00 \AA$ A. Previous DFT calculations using PBE-D2 [26] also showed that as the coverage of the chemisorbed oxygen on $\mathrm{Ru}(0001)$ increases from $n=0$ to $n=4, d\left(\mathrm{Ru}-\mathrm{O}_{\mathrm{Si}}\right)$ by $0.93 \AA$ [16]. During this process, the thickness of the silica films $(d(\mathrm{O}-\mathrm{O}))$ remains intact as shown in Fig. 3.

At the silica/O- $\mathrm{Ru}(0001)$ heterojunction, multiple mechanisms may contribute to the formation of surface or interface dipole moments. The first one is the "push-back" effect [41], where the Pauli repulsion due to the silica film suppresses the tail of metal surface electrons that spill out into the vacuum. In addition, the chemisorbed $\mathrm{O}$ atoms on $\mathrm{Ru}(0001)$ can also cause charge redistributions through the $\mathrm{Ru}-\mathrm{O}$ hybridization [42], which we refer to as the surface surface dipole at the $\mathrm{O}-\mathrm{Ru}(0001)$ surface. Furthermore, the charge transfer. The surface charge transfer can cause a 

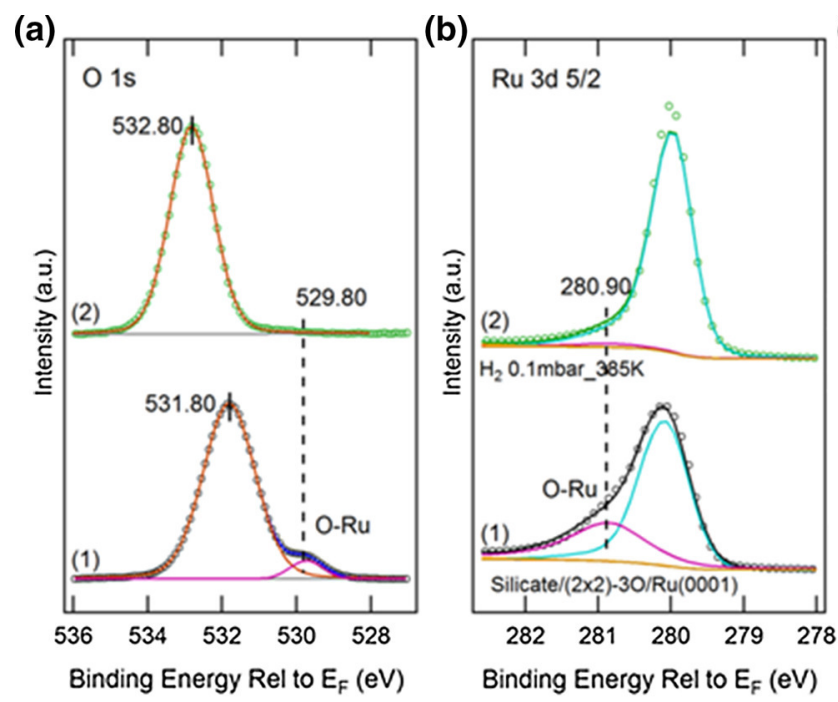

Fig. 2 Reversible tuning of the interfacial chemisorbed oxygen coverage. AP-XPS $(\mathrm{h} v=750 \mathrm{eV})$ core level spectra of a O $1 \mathrm{~s}, \mathbf{b} \mathrm{Ru}$ $3 \mathrm{~d}$, c Si $2 \mathrm{p}$ and $\mathbf{d}$ valence band. The black spectrum is obtained in UHV after annealing the film in $2 \times 10^{-4}$ mbar of $\mathrm{O}_{2}$ at $820 \mathrm{~K}$ (with
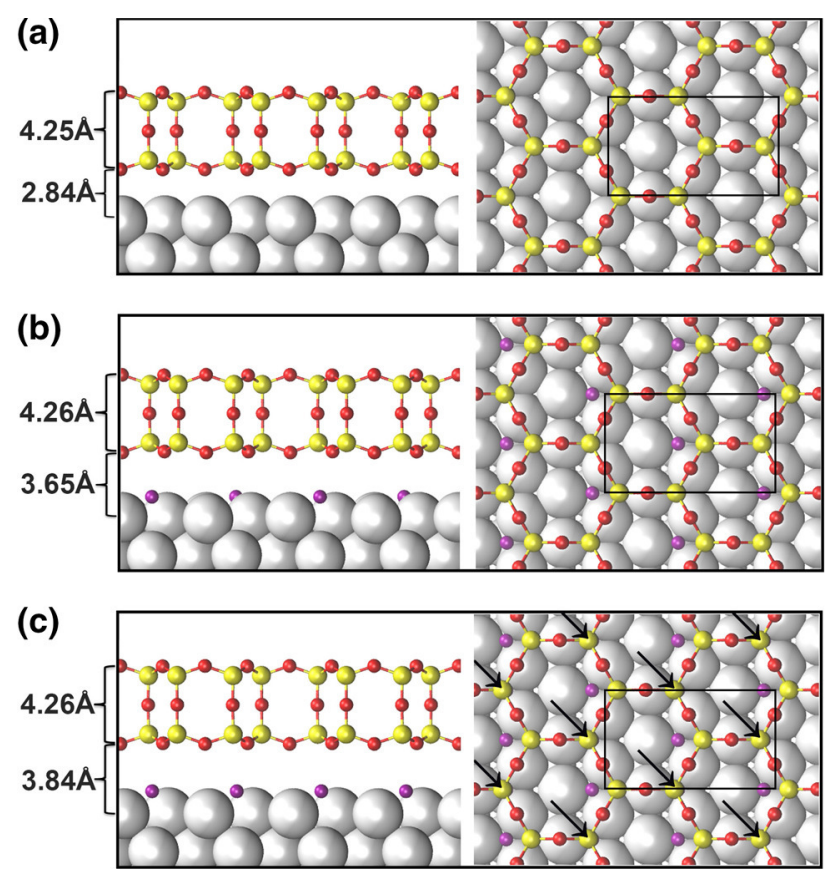

Fig. 3 Side (left) and top (right) view of relaxed structures of a $\left(\mathrm{SiO}_{2}\right)_{8} / 0 \mathrm{O} / \mathrm{Ru}(0001), \mathbf{b}\left(\mathrm{SiO}_{2}\right)_{8} / 2 \mathrm{O} / \mathrm{Ru}(0001)$, and c $\left(\mathrm{SiO}_{2}\right)_{8} / 4 \mathrm{O} /$ $\mathrm{Ru}(0001)$. Black rectangles indicate the unit cell. Color code: $\mathrm{Ru}$ (silver), $\mathrm{Si}$ (yellow), $\mathrm{O}$ in silica films (red), and $\mathrm{O}$ chemisorbed on $\mathrm{Ru}(0001)$ (purple). Black arrows in top view of (c) indicate the location of chemisorbed oxygen atoms underneath silicon atoms (two per unit cell). Distances on the left correspond to the thickness of the silica films $(d(\mathrm{O}-\mathrm{O}))$ and interlayer distances $\left(d\left(\mathrm{Ru}-\mathrm{O}_{\mathrm{Si}}\right)\right)$

quadrupole moment of the silica film can induce dipole moments on the substrate. Finally, unsaturated electrons in $\mathrm{O}$ atoms at the bottom layer of the silica film may tunnel
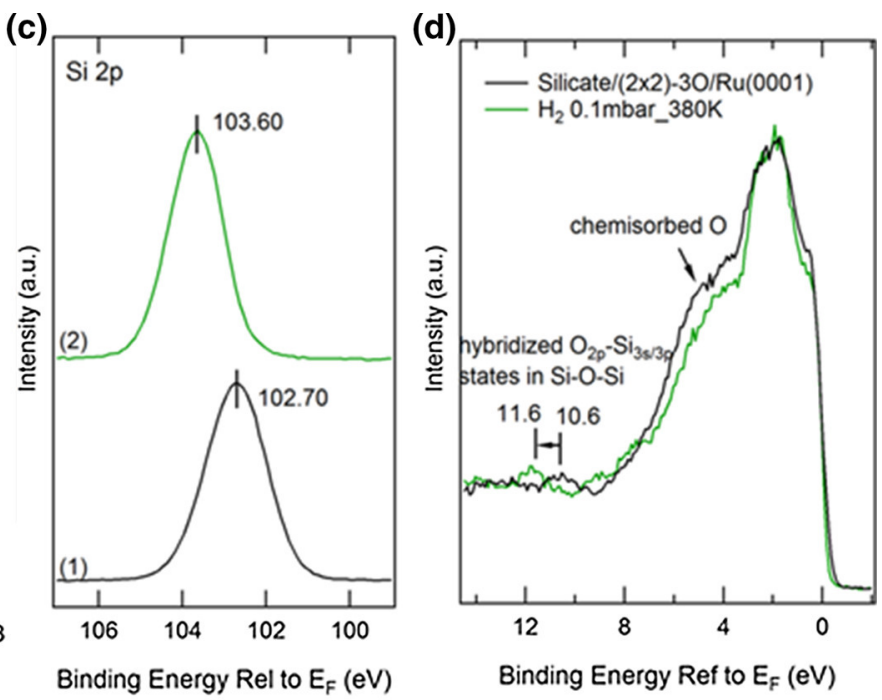

interfacial chemisorbed oxygen coverage of $0.75 \mathrm{ML}$ ), and the green spectrum is taken under 0.1 mbar of $\mathrm{H}_{2}$ at $380 \mathrm{~K}$. (with interfacial chemisorbed oxygen coverage of $0.08 \mathrm{ML}$ )

into the unoccupied $\mathrm{Ru} d$-bands, which we refer to as the interfacial charge transfer. Only in the interfacial charge transfer mechanism, there is a substantial net charge transfer between the silica film and O-Ru(0001), i.e., across the heterojuction, which leads to an interface dipole at the heterojunction.

Interface dipoles caused by charge transfer across distances of 3-4 $\AA$ have been reported at the graphene/molecule interface [43] and the $\mathrm{NO} / \mathrm{SnS}_{2}$ interface [44], and predicted by DFT at the metal/graphene interface [45] and the 3, 4, 9, 10-perylene tetracarboxylic dianhydride/ $\operatorname{Ag}(111)$ interface [46]. Hofmann et al. attributed the reduction of metal work function in Tetrathiafulvalene/ $\mathrm{Au}(111)$ and Viologen/ $\mathrm{Au}(111)$ to the charge transfer from organic molecules to $\mathrm{Au}(111)$ that is about $3 \AA$ away [47].

Here, the interactions among $\mathrm{Ru}$ substrate, $\mathrm{O}(\mathrm{Ru})$, and the silica film can cause a significant charge redistribution, which leads to the formation of dipole moments and changes in the work function. The dominating contributions arise from two types of dipole moments at $\left(\mathrm{SiO}_{2}\right)_{8} /$ $n \mathrm{O} / \mathrm{Ru}(0001)$ heterojunctions: surface dipole moments $\left(p_{\text {sur }}\right)$ due to the charge transfer between $\mathrm{Ru}(0001)$ and $\mathrm{O}(\mathrm{Ru})$, and interface dipole moments $\left(p_{\text {inter }}\right)$ due to the interfacial charge transfer between silica films and $n \mathrm{O} /$ $\mathrm{Ru}(0001)$ substrates. We calculated the plane-averaged charge density differences between the charge densities of the combined systems and the superimposed charge densities of the individual systems: $\Delta \rho_{\text {sur }}=\rho_{n O / R u}-\left(\rho_{O}+\right.$ $\left.\rho_{R u}\right)$, and $\Delta \rho_{\text {inter }}=\rho_{\mathrm{SiO}_{2} / n o / R u}-\left(\rho_{\mathrm{SiO}_{2}}+\rho_{n O / R u}\right)$. As shown in Fig. $4, \Delta \rho_{\text {inter }}$ spreads across the interface with a nodal plane between silica films and the $n \mathrm{O} / \mathrm{Ru}(0001)$ 
Fig. 4 Plane-averaged electron density difference $\Delta \rho_{\text {sur }}$ and $\Delta \rho_{\text {inter }}$ (per unit cell). $\Delta q$ is the number of electrons calculated by integrating $\Delta \rho$ from the bottom of the substrate at $z=0$ to the nodal plane at $z=z_{0}$ (open black circle). $p$ [ $p_{\text {inter }}$ is calculated using $p_{\text {inter }}=$

$p_{\mathrm{SiO}_{2} / n \mathrm{nO} / \mathrm{Ru}}-p_{\text {sur }}-p_{\mathrm{SiO}_{2}}$. For the system with $n=0$, $p_{\mathrm{SiO}_{2}}=-0.04 \mathrm{e} \AA$ while for systems with $\mathrm{n}=2$ and $4, p_{\mathrm{SiO}_{2}}$ becomes negligible] (in $\mathrm{e} \AA$ ) is the dipole moment caused by $\Delta \rho$

(SiO2)8/00/Ru(0001)

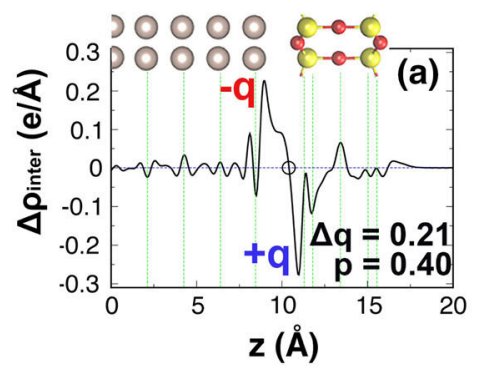

(SiO2)8/2O/Ru(0001)
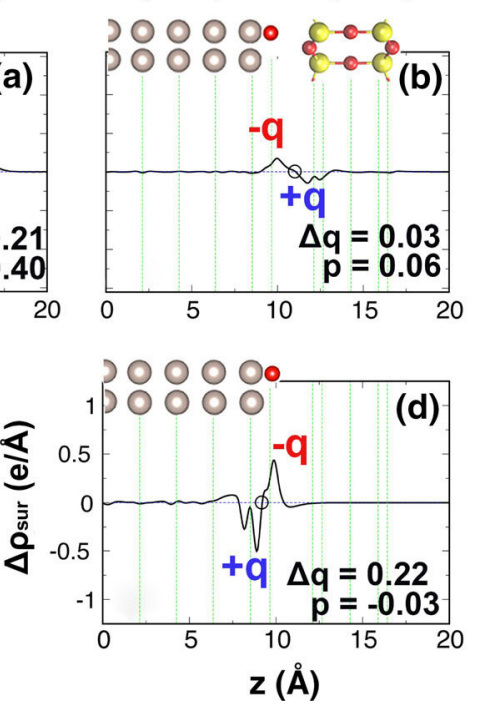

(SiO2)8/4O/Ru(0001)
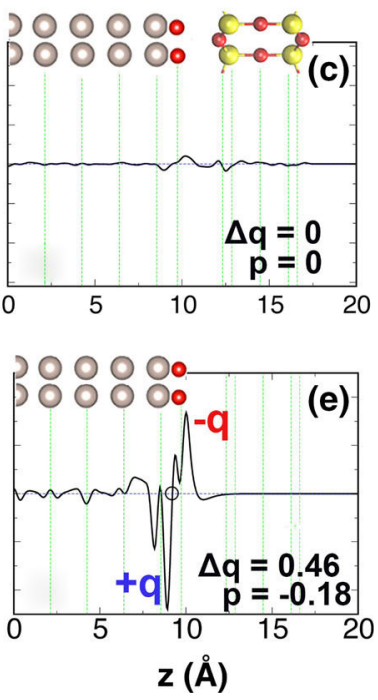

substrates. It corresponds to a positive dipole moment along $z$ (Fig. $4 \mathrm{a}-\mathrm{c}$ ), which can be attributed to electron tunneling from silica films to the $n \mathrm{O} / \mathrm{Ru}(0001)$ substrate. On the other hand, $\mathrm{O}(\mathrm{Ru})$ draws electrons from $\mathrm{Ru}(0001)$, forming negative dipole moments along $z$ (Fig. $4 \mathrm{~d}$ and $4 \mathrm{e}$ ). The magnitude of the charge transfer per unit cell $(\Delta q)$ was calculated by integrating the $\Delta \rho_{\text {sur }}$ and $\Delta \rho_{\text {inter }}$ along $z$.

In order to understand the nature of the interfacial charge transfer, we performed electronic structure analysis of the $\left(\mathrm{SiO}_{2}\right)_{8} / \mathrm{Ru}(0001)$ interface. As shown in the isosurface of the charge difference in Fig. 5a, the bottom layer $\mathrm{O}$ atoms of the silica film lose electrons, while the top layer of $\mathrm{Ru}(0001)$ gain electrons. A nodal plane is formed at 1.98 $\AA$ above the top layer of $\mathrm{Ru}(0001)$ and $0.86 \AA$ below the bottom layer of the silica film, supporting the interfacial charge transfer mechanism. The shaded green area around the top layer of $\mathrm{Ru}(0001)$ is likely caused by the 'pushback' effect and the quadrupole induced dipole moment [48]. Furthermore, Fig. 5a suggests the electron depletion in the $\mathrm{O} p_{\mathrm{z}}$ orbitals and the electron accumulation in the $\mathrm{Ru}$ $d_{x z}$ and $d_{y z}$ orbitals.

In Fig. 5, we plot the projected density of states (PDOS) of the $p_{x}, p_{y}$ and $p_{z}$ orbitals of the bottom $\mathrm{O}$ layer of the freestanding (Fig. 5c) and adsorbed silica film (Fig. 5d), and the PDOS of the $d_{x z}$ (Fig. 5e) and $d_{y z}$ (Fig. 5f) orbitals of the top layer of Ru(0001). In Figs. 5c and 5d, the PDOS are aligned at the valence band maximum (VBM) of the freestanding and adsorbed silica film, and the PDOS in Figs. 5e and $5 \mathrm{f}$ are aligned at the Fermi level. The PDOS of the freestanding silica film displays a sharp peak in $p_{z}$ near VBM. This peak disappears in the PDOS of the adsorbed silica film, indicating significant electron depletion from $p_{z}$ orbitals. Accordingly, there is an increase in the occupied PDOS of the Ru $d_{x z}$ and $d_{y z}$ orbitals near the Fermi level upon the physisorption, indicating electron density accumulation in $d_{x z}$ and $d_{y z}$ orbitals of the top layer of $\mathrm{Ru}(0001)$.

The interfacial charge transfer can occur at a short distance when electrons can tunnel from the silica film to the substrate. As the separation increases, one expects an exponential decay of the amount of tunneling electrons [49]. To verify this point, we gradually increased the distance between silica films and $\mathrm{Ru}(0001)\left(d\left(\mathrm{Ru}-\mathrm{O}_{\mathrm{Si}}\right)\right)$ from the equilibrium distance of $2.84 \AA$ to a larger separation of $3.84 \AA$. The corresponding charge density difference $\left(\Delta \rho_{\text {inter }}\right)$ and the integrated amount of the charge transfer $(\Delta q)$ at different separation distances are shown in Figure S1. In Fig. 5b, we found an evident exponential decay of the net charge transfer with a decay length of $1.00 \AA$.

At $n=0$, the dominating factor is the interfacial charge transfer with $\Delta q_{\text {inter }}=0.21$ electrons and $p_{\text {inter }}=0.40 \mathrm{e \AA}$ (Fig. 4a). The interface dipole moment causes the work function to decrease by $1.24 \mathrm{eV}$ as compared to $\mathrm{Ru}(0001)$ (see Table 1). At $n=2$, as the oxygen coverage increases, $d\left(\mathrm{Ru}-\mathrm{O}_{\mathrm{Si}}\right)$ increases by $0.81 \AA$. Consequently, $\Delta q_{\text {inter }}$ decreases to 0.03 electrons, and $p_{\text {inter }}$ drops to $0.06 \mathrm{e} \AA$. On the other hand, $\mathrm{O}(\mathrm{Ru})$ draw 0.22 electrons from $\mathrm{Ru}(0001)$, which leads to $p_{\text {sur }}=-0.03$ eA (Fig. 4b). As $p_{\text {inter }}$ and $p_{\text {sur }}$ nearly cancel each other, the net dipole moment $\left(p_{\text {tot }}\right)$ of $\left(\mathrm{SiO}_{2}\right)_{8} / 2 \mathrm{O} / \mathrm{Ru}(0001)$ becomes $0.03 \mathrm{e} \AA$, and work function slightly increases by $0.04 \mathrm{eV}$ as compared to $\mathrm{Ru}(0001)$. At $n=4, d(\mathrm{Ru}-\mathrm{O})$ increases to $3.84 \AA$ and $\Delta q_{\text {inter }}$ becomes negligible. In the end, $p_{\text {tot }}$ is dominated by the surface dipole moment $(-0.18 \mathrm{e} \AA)$, leading to a work function increase by $0.81 \mathrm{eV}$ as compared to $\mathrm{Ru}(0001)$.

According to previous experimental studies, surface bound oxygen species greatly affect the work function of the $\mathrm{Ru}$ substrate, which ranges from $\sim 5.3$ to $\sim 6.7 \mathrm{eV}$ 

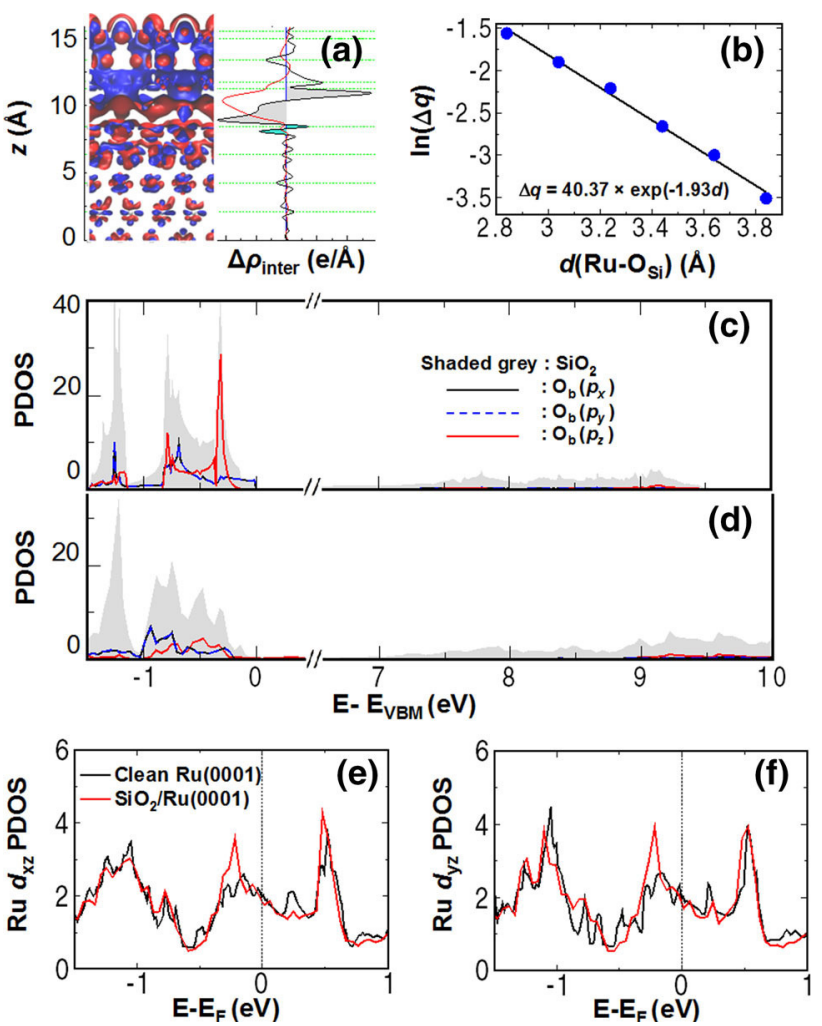

Fig. 5 a Isosurface plot of the charge density difference upon adsorption of $\mathrm{SiO}_{2}$ on $\mathrm{Ru}(0001)$ with an isodensity value of $0.01 \mathrm{e}^{\circ} \AA^{3}$. Red: electron accumulation regions; Blue: electron depletion regions. Plane-averaged electron density difference $\Delta \rho_{\text {inter }}$ is shown on the right. The black line corresponds to $\Delta \rho_{\text {inter }}$, and the red line is the integration of $\Delta \rho_{\text {inter }}$ with respect to $z$. b Net tunneling electrons with respect to the interface separation $d\left(\mathrm{Ru}-\mathrm{O}_{\mathrm{Si}}\right)$. $\mathbf{c}$ PDOS of the $p_{x}, p_{y}$ and $p_{z}$ orbitals for the bottom layer of $\mathrm{O}$ atoms $\left(\mathrm{O}_{\mathrm{b}}\right)$ of the freestanding silica films. Shaded area is the DOS of the freestanding silica films. The energy is relative to the valence band maximum (VBM) of the silica film. d PDOS of the $p_{x}$, $p_{y}$ and $p_{z}$ orbitals of the bottom layer $\mathrm{O}$ atoms $\left(\mathrm{O}_{\mathrm{b}}\right)$ in the adsorbed silica films in $\left(\mathrm{SiO}_{2}\right)_{8} / \mathrm{Ru}(0001)$. Shaded area is the PDOS of the adsorbed silica films. The energy is relative VBM of the adsorbed silica film. e PDOS of the $d_{x z}$ orbitals of the top layer Ru atoms in the clean $\mathrm{Ru}(0001)$ (black line) and $\left(\mathrm{SiO}_{2}\right)_{8} / \mathrm{Ru}(0001)$ (red line). $\mathbf{f} \mathrm{PDOS}$ of the $d_{y z}$ orbitals of the top layer $\mathrm{Ru}$ atoms of the clean $\mathrm{Ru}(0001)$ (black line) and $\left(\mathrm{SiO}_{2}\right)_{8} / \mathrm{Ru}(0001)$ (red line)

[42], and the work function change of the substrate can further affect the interfacial charge transfer between the adsorbed molecule and the substrate [50]. To rationalize the charge transfer contribution to the potential change upon silica films adsorption, we use a plane capacitor model [45] combined with the Helmholtz equation [51], $\Delta V=p / \varepsilon \varepsilon_{0}$, where $\Delta V, p, \varepsilon_{0}$ and $\varepsilon$ are the change of the surface potential, the dipole moment per unit cell caused by the interfacial charge transfer, the dielectric constant of vacuum and the relative dielectric constant, respectively. $\varepsilon$ is calculated to be 1.35 in $\left(\mathrm{SiO}_{2}\right)_{8} / 2 \mathrm{O} / \mathrm{Ru}(0001)$ and used to interpret experimental results. $\Delta q$ can be calculated from $\Delta q=\boldsymbol{p} / z_{d}$ where $z_{d}$ is the effective distance between the sheets of the plane capacitor. $z_{d}$ for $\left(\mathrm{SiO}_{2}\right)_{8} / 2 \mathrm{O} / \mathrm{Ru}(0001)$ is $2 \AA$, which is smaller than $d\left(\mathrm{Ru}-\mathrm{O}_{\mathrm{Si}}\right)$ by a constant $d_{0}$ defined as $d_{0}=d\left(\mathrm{Ru}-\mathrm{O}_{\mathrm{Si}}\right)-z_{d} \cdot d\left(\mathrm{Ru}-\mathrm{O}_{\mathrm{Si}}\right)$ is linearly extrapolated from that of $\left(\mathrm{SiO}_{2}\right)_{8} / 2 \mathrm{O} / \mathrm{Ru}(0001)(0.25 \mathrm{ML})$ and $\left(\mathrm{SiO}_{2}\right)_{8} / 4 \mathrm{O} / \mathrm{Ru}(0001)(0.5 \mathrm{ML})$ in Fig. 1 for 0.2 and $0.42 \mathrm{ML}$. When the coverage of interfacial oxygen is $\sim 0.2$ ML in the experiment, the work function of the surface decreases $0.09 \mathrm{eV}$ upon silica film adsorption while the estimated interfacial charge transfer is 0.017 electrons per unit cell from the silica film to the Ru substrate. In comparison, when the coverage of the interfacial oxygen is increased to $\sim 0.42 \mathrm{ML}$, the work function of the surface increases $0.31 \mathrm{eV}$ upon adsorption of the silica film. We estimate the magnitude of the charge transfer to be 0.055 electrons per unit cell from the Ru substrate to the adsorbed silica film.

In the range of oxygen coverage we studied, $p_{\text {tot }}$ of $\left(\mathrm{SiO}_{2}\right)_{8} / n \mathrm{O} / \mathrm{Ru}(0001)$ decays as a function of $n$, as $p_{\text {sur }}$ increases and $p_{\text {inter }}$ decreases. The impact of $p_{\text {tot }}$ on the energy levels can be understood from the plane-averaged electrostatic potential calculated for the clean $\mathrm{Ru}(0001)$, freestanding silica films, and physisorbed silica films at different $n$ shown in Fig. 6. The Fermi levels $\left(E_{\mathrm{F}}\right)$ of $\left(\mathrm{SiO}_{2}\right)_{8} / n \mathrm{O} / \mathrm{Ru}(0001)$ are aligned with that of the $\mathrm{Ru}(0001)$. The work function $(\Phi)$ of the clean $\mathrm{Ru}(0001)$ is $5.12 \mathrm{eV}$, which is measured as the difference between $E_{\mathrm{F}}$ and the vacuum energy level $\left(E_{\mathrm{vac}}\right)$. The ionization potential (IP) of the silica film is $7.96 \mathrm{eV}$, which is measured as the energy difference between VBM and $E_{\mathrm{vac}}$. When $E_{\mathrm{vac}}$ of the clean $\mathrm{Ru}(0001)$ and freestanding silica films are aligned, the energy separation $(\Delta E)$ between $E_{\mathrm{F}}$ of the $\mathrm{Ru}(0001)$ and VBM of silica films is $2.84 \mathrm{eV}$. When the silica film is
Table 1 Dipole moment (in $\mathrm{e} \AA$ ) and work function (in eV) of $\mathrm{Ru}(0001), n \mathrm{O} / \mathrm{Ru}(0001)$ and $\left(\mathrm{SiO}_{2}\right)_{8} / n \mathrm{O} / \mathrm{Ru}(0001)$ for $n=0$, 2,4

\begin{tabular}{|c|c|c|c|c|c|c|c|}
\hline & \multirow{2}{*}{$\begin{array}{l}\mathrm{Ru}(0001) \\
\mathrm{Ru}\end{array}$} & \multicolumn{2}{|c|}{$\left(\mathrm{SiO}_{2}\right)_{8} / 0 \mathrm{O} / \mathrm{Ru}(0001)$} & \multicolumn{2}{|c|}{$\left(\mathrm{SiO}_{2}\right)_{8} / 2 \mathrm{O} / \mathrm{Ru}(0001)$} & \multicolumn{2}{|c|}{$\left(\mathrm{SiO}_{2}\right)_{8} / 4 \mathrm{O} / \mathrm{Ru}(0001)$} \\
\hline & & $\mathrm{Ru}$ & $\mathrm{Ru} /\left(\mathrm{SiO}_{2}\right)$ & $\mathrm{Ru} / \mathrm{O}$ & $\mathrm{Ru} / \mathrm{O} /\left(\mathrm{SiO}_{2}\right)$ & $\mathrm{Ru} / \mathrm{O}$ & $\mathrm{Ru} / \mathrm{O} /\left(\mathrm{SiO}_{2}\right)$ \\
\hline$p$ & 0.02 & 0.02 & 0.38 & -0.03 & 0.03 & -0.18 & -0.18 \\
\hline$\Phi$ & $\begin{array}{l}5.12^{\dagger} \\
(5.37)\end{array}$ & 5.12 & 3.88 & 5.32 & 5.16 & 5.89 & 5.93 \\
\hline
\end{tabular}

The number in parenthesis is the experimental value

$\dagger$ The work function of the clean $\mathrm{Ru}(0001)$ with top two layers allowed to relax. $\Phi=5.03 \mathrm{eV}$ was reported by Kim et al. [42] 


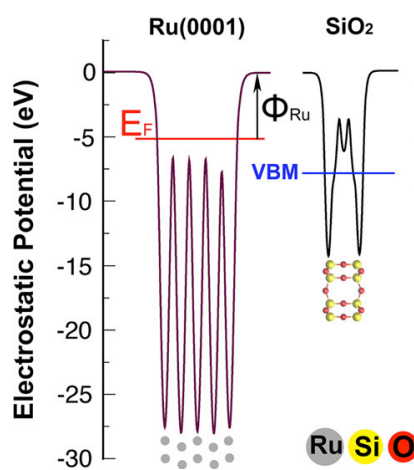

Fig. 6 Plane-averaged electrostatic potential for $\mathrm{Ru}(0001)$, freestanding silica films, and physisorbed silica films in $\left(\mathrm{SiO}_{2}\right)_{8} / n \mathrm{O} /$ $\mathrm{Ru}(0001)$, where $n=0,2,4$. Red lines indicate Fermi levels, and blue lines indicate VBMs

physisorbed on the clean $\mathrm{Ru}(0001), p_{\text {inter }}$ causes a drop of $E_{\mathrm{vac}}$ and $\mathrm{VBM}$ of the physisorbed silica film. $\Delta E$ thus becomes $3.87 \mathrm{eV}$. As $n$ increases, VBM of silica films moves closer to the Fermi level, due to the decrease of $p_{\text {tot }}$. The decay trend of $\Delta E$ as a function of $n$ (Table 2) is generally consistent with experimentally observed $\mathrm{O} 1 \mathrm{~s}$ and Si $2 p$ binding energy $\left(E_{B E}\right)$ downward shift during the $\mathrm{Ru}(0001)$ surface oxidation. This indicates that the corelevel binding energy shift $\left(\Delta E_{B E}\right)$ in silica film during surface oxidation is caused by the surface and interface dipole fields.

The calculated layer-resolved $E_{B E}$ of the $\mathrm{O} 1 \mathrm{~s}$ core levels, relative to that of $\mathrm{O}(\mathrm{Ru})$ in $\left(\mathrm{SiO}_{2}\right)_{8} / 4 \mathrm{O} / \mathrm{Ru}(0001)$, are shown in Table 2. The comparison with experimental results is shown in Fig. 7. All $E_{B E}$ values are extrapolated to infinite supercell limit. The values of $E_{B E}$ calculated for the $2 \times 2,4 \times 2$ and $8 \times 4$ unit cells are summarized in Table 2 in the Supporting Information. As $n$ increases from 2 to 4 , the $E_{B E}$ of $\mathrm{O}(\mathrm{Ru})$ changes only $0.09 \mathrm{eV}$, in good agreement with the experiment. The average $E_{B E}$ of $\mathrm{O}(\mathrm{Si})$ is $3.32,2.11$ and $1.52 \mathrm{eV}$ for $n=0,2$ and 4, respectively,

Table 2 Simulated core level binding energy $\left(E_{B E}\right.$ in DFT) for chemisorbed oxygen on $\mathrm{Ru}(0001)(\mathrm{O}(\mathrm{Ru}))$ and oxygen in silica films $(\mathrm{O}(\mathrm{Si}))$ in $\left(\mathrm{SiO}_{2}\right)_{8} / n \mathrm{O} / \mathrm{Ru}(0001)$ where $n=0,2,4$ and XPS core level binding energy $\left(E_{B E}\right.$ in XPS) for $\mathrm{O}(\mathrm{Ru})$ and $\mathrm{O}(\mathrm{Si})$ in $\left(\mathrm{SiO}_{2}\right)_{8} / n \mathrm{O} /$ $\mathrm{Ru}(0001)$ where $n=0.56,2.00,3.36 . \mathrm{O}_{t}(\mathrm{Si}), \mathrm{O}_{m}(\mathrm{Si})$, and $\mathrm{O}_{b}(\mathrm{Si})$ in DFT stand for $E_{B E}$ for top, middle and bottom O layer in silica films,

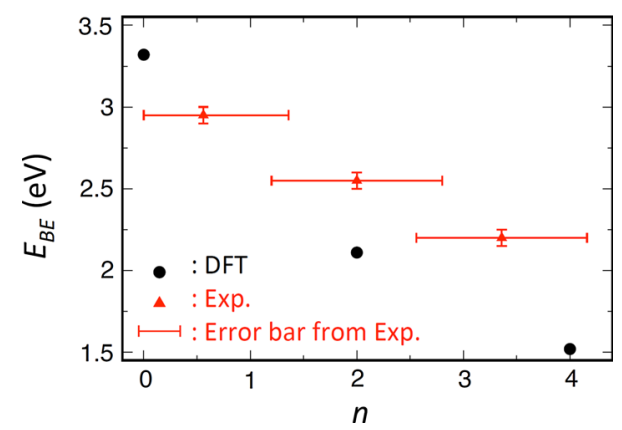

Fig. 7 Average core level binding energy $\left(E_{B E}\right)$ for oxygen in silica films in $\left(\mathrm{SiO}_{2}\right)_{8} / n \mathrm{O} / \mathrm{Ru}(0001)$ from DFT (Black dot) and XPS experiments (Red triangle). Red lines represent error bars from experiments

corresponding to $\Delta E_{B E}=-1.80 \mathrm{eV}$. In the core-level XPS spectra in Fig. 1e, the corresponding $\Delta E_{B E}$ is $-0.75 \mathrm{eV}$, when the coverage of $\mathrm{O}(\mathrm{Ru})$ increases from $0.07 \mathrm{ML}$ $(n \approx 0.56)$ to $0.42 \mathrm{ML}(n \approx 3.36)$ during the oxidation process. The decreasing trend of $E_{B E}$ qualitatively agrees with experiment. However, the magnitude of the calculated $\Delta E_{B E}$ is larger than the experimental value. Various factors may contribute to this difference. Experimentally, the estimate of oxygen coverage from normalized XPS peak intensities has an error of $\pm 0.1 \mathrm{ML}$, and the error bar for the core level binding energy is $\pm 0.05 \mathrm{eV}$. On the other hand, approximations used in the $E_{B E}$ simulation (e.g., treating XPS with a neutral excitation instead of a charged excitation) may also introduce errors. The $E_{B E}$ of $\mathrm{O}(\mathrm{Si})$, resolved by layers, show a spread of $0.82,0.63$ and $0.51 \mathrm{eV}$ for $n=0,2$ and 4 because of the different chemical environments of the $\mathrm{O}$ atoms in the two different layers. In the core-level XPS spectra (Fig. 1a), the FWHM of $\mathrm{O}(\mathrm{Si}$ ) is $1.6 \mathrm{eV}$ while $\mathrm{O}(\mathrm{Ru})$ is $1.0 \mathrm{eV}$. The FWHM difference of $0.6 \mathrm{eV}$ between $\mathrm{O}(\mathrm{Ru})$ and $\mathrm{O}(\mathrm{Si})$ can be related to the different binding energies calculated for $\mathrm{O}$ in the different layers of the silica framework.

and $\mathrm{O}_{\text {ave }}(\mathrm{Si})$ stands for the average $E_{B E}$ of all $\mathrm{O}$ atoms in silica films. All $E_{B E}$ values are relative to that of $\mathrm{O}(\mathrm{Ru})$ in $\left(\mathrm{SiO}_{2}\right)_{8} / 4 \mathrm{O} / \mathrm{Ru}(0001)$. The energy separations ( $\Delta E$, see Fig. 5) are calculated as the difference between $E_{\mathrm{F}}$ of $\left(\mathrm{SiO}_{2}\right)_{8} / n \mathrm{O} / \mathrm{Ru}(0001)$ and $\mathrm{VBM}$ of silica films. The energy unit is $\mathrm{eV}$

\begin{tabular}{|c|c|c|c|c|c|c|}
\hline & & & & $N=0$ & $N=2$ & $N=4$ \\
\hline \multirow[t]{6}{*}{ DFT } & $E_{B E}$ & $\mathrm{O}(\mathrm{Si})$ & $\mathrm{O}_{t}(\mathrm{Si})$ & 3.74 & 2.47 & 1.82 \\
\hline & & & $\mathrm{O}_{m}(\mathrm{Si})$ & 3.28 & 1.98 & 1.37 \\
\hline & & & $\mathrm{O}_{b}(\mathrm{Si})$ & 2.92 & 1.84 & 1.31 \\
\hline & & & $\mathrm{O}_{\text {ave }}(\mathrm{Si})$ & 3.32 & 2.11 & 1.52 \\
\hline & & $\mathrm{O}(\mathrm{Ru})$ & & - & 0.09 & 0 \\
\hline & $\Delta E$ & & & 3.87 & 2.87 & 2.07 \\
\hline XPS & $E_{B E}$ & $\mathrm{O}(\mathrm{Si})$ & \multicolumn{4}{|c|}{$2.95(n \approx 0.56) 2.55(n \approx 2.00) 2.20(n \approx 3.36)$} \\
\hline
\end{tabular}


Fig. 8 Schematic diagrams showing interfacial chemisorbed oxygen dependent energy levels at the silica/ $\mathrm{Ru}(0001)$ heterojuction (a) $\left(\mathrm{SiO}_{2}\right)_{8} / 00 / \mathrm{Ru}(0001)$

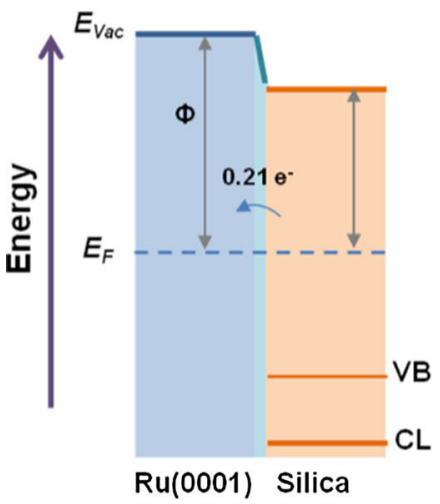

(b) $\left(\mathrm{SiO}_{2}\right)_{8} / 2 \mathrm{O} / \mathrm{Ru}(0001)$

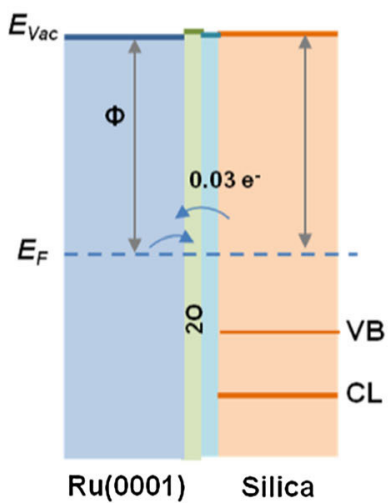

(c) $\left(\mathrm{SiO}_{2}\right)_{8} / 4 \mathrm{O} / \mathrm{Ru}(0001)$

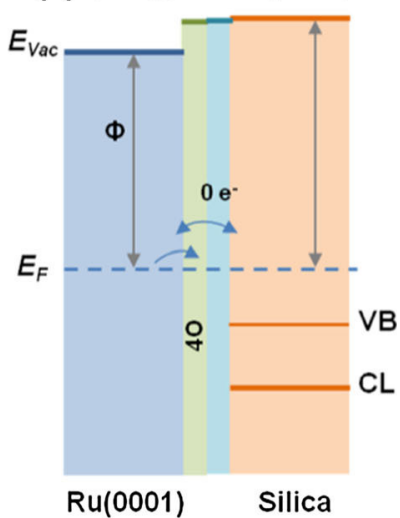

The surface and interfacial charge transfer and corresponding energy level shifts are schematically shown in Fig. 8. The charge transfer from $\mathrm{Ru}(0001)$ to $\mathrm{O}(\mathrm{Ru})$ results in negative surface dipole moments, while the interfacial charge transfer from silica films to the Ru substrate leads to positive interface dipole moments. During the oxidation of the $\mathrm{Ru}$ substrate, these two competing effects gradually increase the work function of $\left(\mathrm{SiO}_{2}\right)_{8} / n \mathrm{O} / \mathrm{Ru}(0001)$ and move the energy levels in the silicate films closer to the Fermi level. As discussed above, the experimentally determined interface dipole moment changes sign starting at a chemisorbed-oxygen coverage of $\sim 0.25 \mathrm{ML}$. Due to the small magnitude of the interfacial charge transfer at a large interfacial distance, the magnitude of the interface dipole moment is smaller than the surface dipole moment.
To further confirm that the energy levels at the silica/ $\mathrm{Ru}(0001)$ heterojunction can be realigned by tuning the chemical states of the $\mathrm{Ru}(0001)$ substrate, we investigated an interface consisting of an aluminosilicate bilayer on $\mathrm{Ru}(0001)$. This is of special importance for catalysis, since these aluminosilicate films have proven to represent good surface science model for zeolites [52]. The aluminosilicate film was composed of an ordered bilayer network of $\left[\mathrm{SiO}_{4}\right]$ and $\left[\mathrm{AlO}_{4}^{-1}\right]$ tetrahedra $\left(\mathrm{Al}_{\mathrm{x}} \mathrm{Si}_{1-\mathrm{x}} \mathrm{O}_{2}\right)$, which is also weakly bound to the Ru substrate [10]. For the case of the aluminosilicate, we expect an additional charge transfer from the $\mathrm{Ru}$ substrate to the aluminosilicate film, to compensate for the charge imbalance introduced in the framework when introducing $\mathrm{Al}$ in tetrahedral positions. In this paper, the aluminosilicate film was prepared with a
Fig. 9 Dependence of energy levels at the bilayer aluminosilicate/ $\mathrm{Ru}(0001)$ heterostructure $\left(\mathrm{Al}_{0.16} \mathrm{Si}_{0.84} \mathrm{O}_{2}\right)$ on the coverage of chemisorbed oxygen. The evolution of the AP-XPS $(\mathrm{h} v=750 \mathrm{eV})$ core level spectra a O $1 \mathrm{~s}$, b Al $2 \mathrm{~s}$, c Si $2 p$ and $\mathbf{d}$ Ru $3 d$ are shown in the figure upon heating the aluminosilicate $/ \mathrm{Ru}(0001)$ from 300 to $840 \mathrm{~K}$ in $2 \times 10^{-4}$ mbar of $\mathrm{O}_{2}$ (the coverage of interfacial chemisorbed oxygen increases from 0.05 to $0.5 \mathrm{ML}$ ) (a)

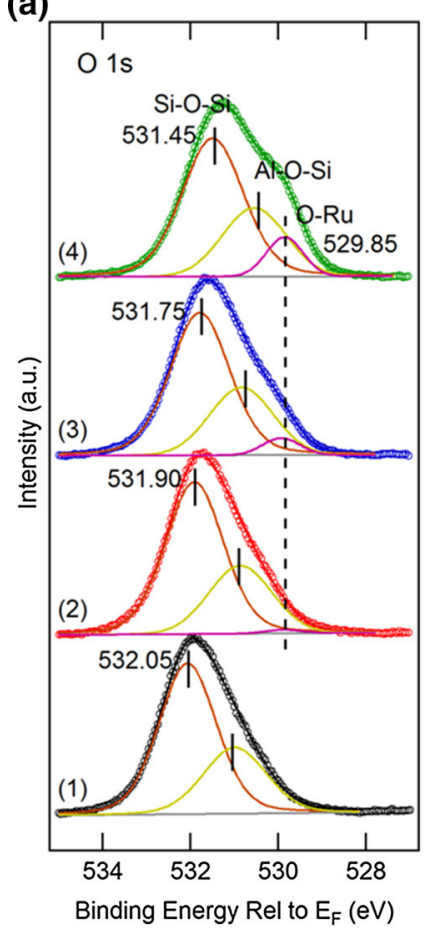

(b)

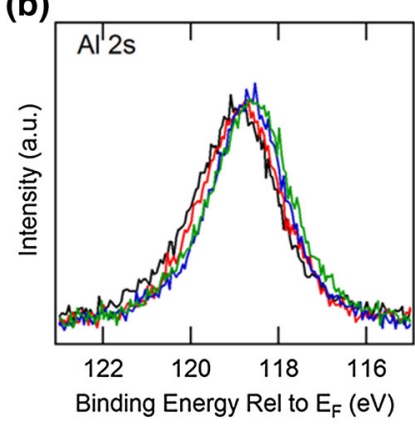

(c)
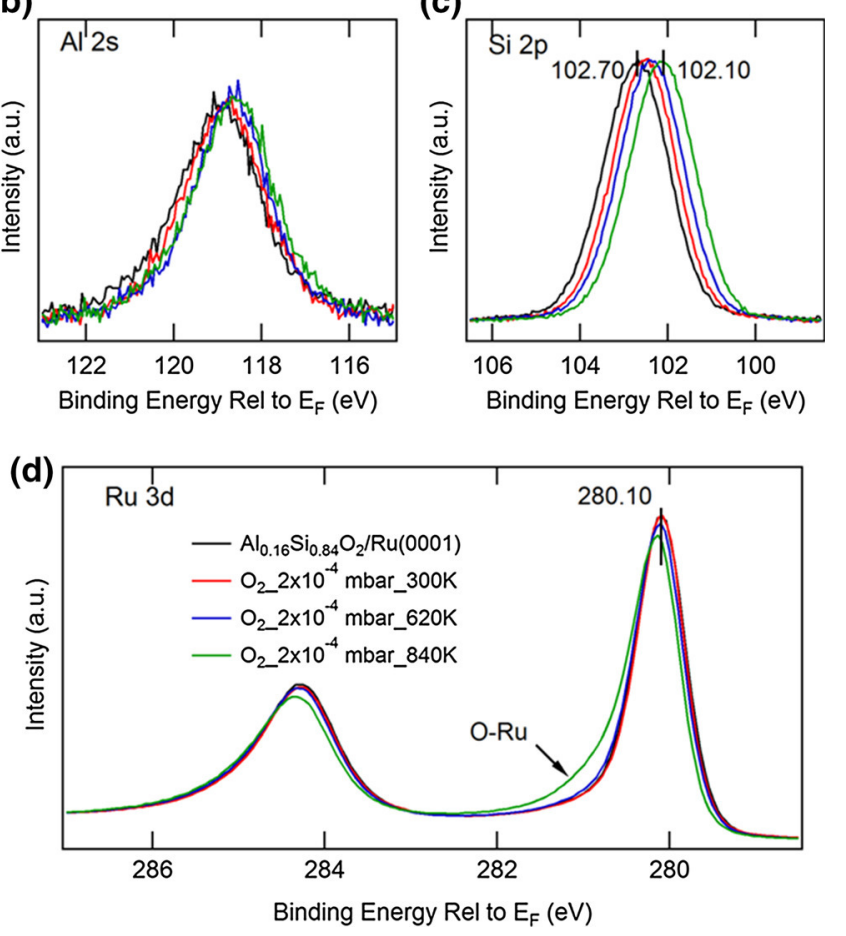
stoichiometry of $\mathrm{Al}_{0.16} \mathrm{Si}_{0.84} \mathrm{O}_{2}$. The "as-prepared" aluminosilicate film was first reduced in hydrogen to remove most of the chemisorbed oxygen at the interface. As shown in Fig. 9a, the $\mathrm{O} 1 \mathrm{~s}$ in the $\mathrm{Al}_{0.16} \mathrm{Si}_{0.84} \mathrm{O}_{2} / \mathrm{Ru}(0001)$ heterostructure develops into two peaks with a main component at $532.05 \mathrm{eV}$ and a shoulder at $531.05 \mathrm{eV}$, which are assigned to the $\mathrm{Si}-\mathrm{O}-\mathrm{Si}$ linkage and $\mathrm{Al}-\mathrm{O}-\mathrm{Si}$ linkage respectively [10]. By oxidizing the film in $2 \times 10^{-4}$ mbar $\mathrm{O}_{2}$, a third oxygen peak appears at a binding energy of $529.85 \mathrm{eV}$, corresponding to the chemisorbed oxygen on the $\mathrm{Ru}(0001)$ substrate. Similarly, all the core levels in the aluminosilicate framework shift to the lower binding energy by $\sim 0.6 \mathrm{eV}$ as shown in Fig. 9a-c, while the chemisorbed oxygen peak still remains at the same binding energy. These energy level shifts are also reversible as observed during the reduction reaction process, which is consistent with the silica/ $\mathrm{Ru}(0001)$ heterojunction.

It should be noted that the $\mathrm{O} 1 s(\mathrm{Si}-\mathrm{O}-\mathrm{Si})$ and $\mathrm{Si} 2 \mathrm{p}$ binding energies in the aluminosilicate/ $\mathrm{Ru}(0001)$ are $\sim 0.7 \mathrm{eV}$ higher than for the silica/Ru(0001), for the $\mathrm{Ru}(0001)$ substrate with a coverage of chemisorbed $\mathrm{O}$ of $\sim 0.05-0.07$ ML (after reduction in $\mathrm{H}_{2}$ ). This can be induced by partial electron transfer from the substrate to the aluminosilicate film in order to compensate the charge imbalance caused by the $\mathrm{Al}$ substitution at the bottom of the aluminosilicate bilayer [10], which will decrease the total dipole moment $\left(\boldsymbol{p}_{\text {tot }}\right)$ across the aluminosilicate/ $\mathrm{Ru}(0001)$ heterojunction. As a result, the observed total energy level shifts in then aluminosilicate $(\sim 0.6 \mathrm{eV})$ is smaller than that in silica $(\sim 0.8 \mathrm{eV})$ when the Ru content of chemisorbed oxygen changes from 0.05 to $0.5 \mathrm{ML}$.

\section{Conclusions}

In summary, a combined in situ XPS and DFT study for the silica/Ru(0001) system reveals the mechanism for core level shifts in silica films as the coverage of chemisorbed oxygen is varied. Although the structures of the silica films are found to stay intact under these reactions, the interface electronic structures can be significantly affected by the chemical states of the $\mathrm{Ru}$ substrate. The interfacial properties, in particular dipole moments due to charge transfer, play essential roles in determining the energy level alignments across the silica/Ru interfaces. Our detailed investigations using the model bilayer-silica/ $\mathrm{Ru}(0001)$ system provide physical insights into the effects of interface electronic properties in silica model systems. Furthermore, this is extended to the case of the bilayer-aluminosilicate/ $\mathrm{Ru}(0001)$, of great importance to catalysis, given its potential as a surface science model system for zeolites.
Acknowledgments Research carried out in part at the Center for Functional Nanomaterials and at the CSX-2 beamline of the National Synchrotron Light Source II, Brookhaven National Laboratory, which is supported by the U.S. Department of Energy, Office of Basic Energy Sciences, under Contract No. DE-SC0012704. J.Q Zhong and M. Wang are supported by BNL LDRD Project No. 15-010. This research used resources of the National Energy Research Scientific Computing Center, a DOE Office of Science User Facility supported by the Office of Science of the U.S. Department of Energy under Contract No. DE-AC02-05CH11231. Helpful discussions with Per Hyldgaard concerning the vdW-DF-cx functional are gratefully acknowledged.

\section{References}

1. Min BK, Santra AK, Goodman DW (2003) Catal Today 85(2-4):113-124

2. Büchner C, Lichtenstein L, Stuckenholz S, Heyde M, Ringleb F, Sterrer M, Kaden WE, Giordano L, Pacchioni G, Freund H-J (2014) J Phys Chemi C 118(36):20959-20969

3. Shaikhutdinov S, Freund H-J (2013) Adv Mater 25(1):49-67

4. Boscoboinik JA, Shaikhutdinov S (2014) Catal Lett 144(12):1987-1995

5. Weissenrieder J, Kaya S, Lu JL, Gao HJ, Shaikhutdinov S, Freund HJ, Sierka M, Todorova TK, Sauer J (2005) Phys Rev Lett 95(7):076103

6. Stacchiola D, Kaya S, Weissenrieder J, Kuhlenbeck H, Shaikhutdinov S, Freund H-J, Sierka M, Todorova TK, Sauer J (2006) Angew Chem Int Ed 45(45):7636-7639

7. Kundu M, Murata Y (2002) Appl Phys Lett 80(11):1921-1923

8. Zhang Z, Jiang Z, Yao Y, Tan D, Fu Q, Bao X (2008) Thin Solid Films 516(12):3741-3746

9. Yang B, Kaden WE, Yu X, Boscoboinik JA, Martynova Y, Lichtenstein L, Heyde M, Sterrer M, Wlodarczyk R, Sierka M, Sauer J, Shaikhutdinov S, Freund H-J (2012) Phys Chem Chem Phys 14(32):11344-11351

10. Boscoboinik JA, Yu X, Yang B, Fischer FD, Włodarczyk R, Sierka M, Shaikhutdinov S, Sauer J, Freund H-J (2012) Angew Chem Int Ed 51(24):6005-6008

11. Emmez E, Yang B, Shaikhutdinov S, Freund H-J (2014) J Phys Chem C 118(50):29034-29042

12. Zhong J-Q, Kestell J, Waluyo I, Wilkins S, Mazzoli C, Barbour A, Kaznatcheev K, Shete M, Tsapatsis M, Boscoboinik JA (2016) J Phys Chem C 120(15):8240-8245

13. Emmez E, Boscoboinik JA, Tenney S, Sutter P, Shaikhutdinov S, Freund H-J (2016) Surf Sci 646:19-25

14. Schlexer P, Pacchioni G, Włodarczyk R, Sauer J (2016) Surf Sci 648:2-9

15. Eichelbaum M, Hävecker M, Heine C, Wernbacher AM, Rosowski F, Trunschke A, Schlögl R (2015) Angew Chem Int Ed 54(10):2922-2926

16. Włodarczyk R, Sierka M, Sauer J, Löffler D, Uhlrich JJ, Yu X, Yang B, Groot IMN, Shaikhutdinov S, Freund HJ (2012) Physical Review B 85(8):085403

17. Kestell JD, Zhong J-Q, Shete M, Waluyo I, Sadowski JT, Stacchiola DJ, Tsapatsis M, Boscoboinik JA (2016) Catalysis Today

18. Kresse G, Furthmüller J (1996) Phys Rev B 54(16):11169

19. Kresse G, Furthmüller J (1996) Comput Mater Sci 6(1):15-50

20. Berland K, Hyldgaard P (2014) Phys Rev B 89(3):035412

21. Bjorkman T (2014) J Chem Phys 141(7):074708

22. Perdew JP, Burke K, Ernzerhof M (1996) Phys Rev Lett 77(18):3865

23. Perdew JP, Burke K, Ernzerhof M (1997) Phys Rev Lett 78:1396 
2. Klimeš J, Bowler DR, Michaelides A (2011) Phys Rev B 83(19):195131

25. Klimes J, Bowler DR, Michaelides A (2010) J Phys 22(2):022201

26. Grimme S (2006) J Comput Chem 27(15):1787-1799

27. Grimme S, Antony J, Ehrlich S, Krieg H (2010) J Chem Phys 132(15): 154104

28. Grimme S, Ehrlich S, Goerigk L (2011) J Comput Chem 32(7):1456-1465

29. Neugebauer J, Scheffler M (1992) Phys Rev B 46(24):16067

30. Janak JF (1978) Phys Rev B 18(12):7165

31. Göransson C, Olovsson W, Abrikosov IA (2005) Phys Rev B 72(13): 134203

32. Lindroos M, Pfnür H, Held G, Menzel D (1989) Surf Sci 222(2-3):451-463

33. Pfnür H, Held G, Lindroos M, Menzel D (1989) Surf Sci 220(1):43-58

34. Kostov KL, Gsell M, Jakob P, Moritz T, Widdra W, Menzel D (1997) Surf Sci 394(1-3):L138-L144

35. Stampfl C, Schwegmann S, Over H, Scheffler M, Ertl G (1996) Phys Rev Lett 77(16):3371-3374

36. Löffler D, Uhlrich JJ, Baron M, Yang B, Yu X, Lichtenstein L, Heinke L, Büchner C, Heyde M, Shaikhutdinov S, Freund HJ, Włodarczyk R, Sierka M, Sauer J (2010) Phys Rev Lett 105(14): 146104

37. Włodarczyk R, Sierka M, Sauer J, Löffler D, Uhlrich JJ, Yu X, Yang B, Groot IMN, Shaikhutdinov S, Freund HJ (2012) Phys Rev B 85(8):085403

38. Klemm HW, Peschel G, Madej E, Fuhrich A, Timm M, Menzel D, Schmidt T, Freund HJ (2016) Surf Sci 643:45-51

39. Blume R, Christen W, Niehus H (2006) J Phys Chem B 110(28): 13912-13919
40. Wendt S, Ozensoy E, Wei T, Frerichs M, Cai Y, Chen MS, Goodman DW (2005) Phys Rev B 72(11):115409

41. Bagus PS, Staemmler V, Wöll C (2002) Phys Rev Lett 89(9):096104

42. Kim YD, Seitsonen AP, Wendt S, Wang J, Fan C, Jacobi K, Over H, Ertl G (2001) J Phys Chem B 105(18):3752-3758

43. Zhong J-Q, Qin X, Zhang J-L, Kera S, Ueno N, Wee ATS, Yang J, Chen W (2014) ACS Nano 8(2):1699-1707

44. Ou JZ, Ge W, Carey B, Daeneke T, Rotbart A, Shan W, Wang Y, Fu Z, Chrimes AF, Wlodarski W (2015) ACS Nano 9(10): 10313-10323

45. Khomyakov PA, Giovannetti G, Rusu PC, Brocks Gv, Van den Brink J, Kelly PJ (2009) Phys Rev 79(19):195425

46. Stadtmüller B, Lüftner D, Willenbockel M, Reinisch EM, Sueyoshi T, Koller G, Soubatch S, Ramsey MG, Puschnig P, Tautz FS, Kumpf C (2014) Nat Commun 5

47. Hofmann OT, Rangger GM, Zojer E (2008) J Phys Chem C 112(51):20357-20365

48. Monti OLA, Steele MP (2010) Phys Chem Chem Phys 12(39):12390-12400

49. Wold DJ, Haag R, Rampi MA, Frisbie CD (2002) J Phys Chem B 106(11):2813-2816

50. Greiner MT, Helander MG, Tang W-M, Wang Z-B, Qiu J, Lu Z-H (2012) Nat Mater 11(1):76-81

51. Bruening M, Cohen R, Guillemoles JF, Moav T, Libman J, Shanzer A, Cahen D (1997) J Am Chem Soc 119(24):5720-5728

52. Boscoboinik JA, Yu X, Emmez E, Yang B, Shaikhutdinov S, Fischer FD, Sauer J, Freund H-J (2013) J Phys Chem C 117(26): 13547-13556 